\title{
The Social Determinants of Food Purchasing Practices: Who Chooses Price-before-Health, Taste-before-Price or Organic Foods in Australia?
}

\author{
Paul R. Ward ${ }^{1}$, Loreen Mamerow ${ }^{1}$, Julie Henderson ${ }^{2}$, Anne W. Taylor ${ }^{3}$, Samantha B. Meyer ${ }^{1}$, \\ John Coveney ${ }^{1}$ \\ ${ }^{1}$ Discipline of Public Health, Flinders University, Adelaide, Australia; ${ }^{2}$ School of Nursing and Midwifery, Flinders University, Ade- \\ laide, Australia; ${ }^{3}$ Population Research and Outcome Studies, University of Adelaide, Adelaide, Australia. \\ Email: paul.ward@flinders.edu.au
}

Received January $12^{\text {th }}, 2012$; revised February $23^{\text {rd }}, 2012$; accepted February $29^{\text {th }}, 2012$

\begin{abstract}
A survey of the extent to which cost, taste and health considerations impact food purchasing practices in Australia was conducted. Data were gathered from a national computer assisted telephone survey of 1109 randomly sampled householders and analysed using multiple logistic regression analysis. $88 \%$ of respondents considered the taste of food before its price, with females and people on higher incomes more likely to do so. $52 \%$ of respondents said that they considered the price of food before its health and nutritional benefits, with males, younger people and people with lower educational qualifications more likely to do so. $49 \%$ said that they purchase organic food, with people with 1 child, full-time employed and people never married more likely to do so. Overall, gender, income, education, work status, age and family size are all important predictors of food purchasing practices in Australia.
\end{abstract}

Keywords: Food; Taste; Price; Organic; Socio-Demographics; Survey; Logistic Regression; Australia

\section{Introduction}

This paper focuses on the extent to which cost, taste, health and ethical considerations impact food purchasing practices (referred to as FPP throughout this paper) in Australia. The specific FPP considered in this paper are: considering food prices before their health or nutritional qualities when purchasing food (i.e. price-before-health); purchasing organic foods (may be related to health and ethical issues); and purchasing foods which are more expensive because they taste better (i.e. taste-beforeprice). The paper provides data from a national survey in Australia about both the prevalence and social determinants of these FPP. By social determinants, we mean the relative effects of factors such as gender, age, income, social class, household size and composition, and educational attainment on FPP. Our paper is timely given the rising food costs, increased focus upon prevention of chronic disease through adoption of healthy diet, and the ethical and environmental considerations in relation to food production and transport. Thus the need to understand changing consumer food-related practices has moved to centre stage in public health policy. In learning the details of everyday dynamics of FPP, this paper will also shed light on the "complex range of factors which operate to produce and/or sustain "unhealthy" lifestyles and (by extension) overweight and obesity" [1].

FPP are embedded in the everyday details of lifewhat French anthropologist Bourdieu [2,3] refers to as the habitus, which is shaped by sociocultural and economic settings. Food and food practices are not only symbolic of, but are deeply engrained bodily performances of identity, class and social relations, and are transmitted, learned and reproduced in families and across generations. These bodily ways of being and knowing are largely unconscious and taken-for-granted. However, Sayer undertakes a critical analysis of habitus, arguing that habitus is more flexible and malleable than Bourdieu originally asserted [4]. Indeed, Sayer argues that it is difficult to see how "resistance" would be possible if individual identity are largely a product (both complying with, and complicit in the production of their habitus) of their social and cultural milieu. Bourdieu [2] argues that each individual is born into particular cultural and class meaning systems that code the body in ways of "standing, speaking and thereby of feeling and thinking" (p. 32). Therefore, the "food practices" within this paper are not simply individual "behaviours", but represent an interrelationship between the individual and the wider classed 
and gendered structures within society.

\section{Consideration of Food Costs as a FPP}

Cost has been identified as a major consideration in food choice [4-7]. As in many other countries, Australian consumers have recently had to accommodate increases in costs of basic food [8]. During the financial year 2007-8, overall food prices rose $3.9 \%$, while some basic food prices rose more sharply: cheese by $14.2 \%$, milk by $12.1 \%$, poultry by $11.0 \%$ and bread by $6.8 \%$ [9]. Food cost plays a significant role in mediating food choice among low socio-economic status (SES) groups [10,11], who often have to cut back on food spending to make room for other essentials such as housing and utilities [12-15], leading to decreased food security [16].

Food insecurity is associated with obesity $[17,18]$ and obesity related disease $[19,20]$. These elevated rates of obesity among the food insecure is thought to result principally from increased consumption of foods high in fat and or sugar that are typically cheaper, more available, heavily marketed and simpler to prepare than healthy alternatives [6,7]. Furthermore, the health consequences of food insecurity go beyond obesity and include nutrient inadequacy [21], self reported health [20] and compromised child health [17]. Data collected in South Australia estimates the food insecurity rate to be approximately $7 \%$ [22]. However, this increases among at-risk groups including: unemployed (11.3\%), rental households (15.8\%) [23], those identifying as Aboriginal or Torres Strait Islander (23\%) [24] and recently arrived refugees $(71 \%)$ [25].

There are a number of recognised social determinants of food insecurity, such as the unaffordability of healthy food for lower SES groups [26,27], rising food prices in Australia [11], higher food prices and greater density of unhealthy food options in socially disadvantaged areas [28,29], employment status [30], educational attainment [31] and access to private transport [32]. We assess a number of these variables, in addition to others, when examining the nature and extent for FPP in Australia.

\section{Purchasing Organic Food as a FPP}

The market for organically produced foods is high within the developed world. In Australia, the organic food market increased to $\$ 947$ Million in 2009, with sales up $50 \%$ from the previous two years [33]. In the UK, organic food sales were over $£ 2$ Billion in 2007, but reduced to $£ 1.8$ Billion by 2009 , possibly due to the economic downturn [34]. Organic food tends to be more expensive than non-organic food, and evidence suggests that consumers are willing to pay the higher price for organic foods based on their perceived health, nutritional and taste benefits [35]. Indeed, a number of studies have found that consumers perceive organic food to be both healthier and of higher nutritional quality than nonorganic food [36-38]. Of particular concern to consumers is the use of pesticides. Canadian research has found that women, people aged 18 to 24 years and from larger households are more concerned with regulation of pesticide use [39]. Conversely, Australian research found significantly less concern with pesticide use among 18 to 24 year olds than older participants [40]. Two recent systematic reviews found however that there is no evidence of nutrition-related health benefits resulting from the consumption of organic food in comparison to nonorganic food $[41,42]$. These systematic reviews did not undertake meta-analyses due to methodological diversity of studies examined and did not examine the public health or environmental benefits of organic food. Nevertheless, the literature suggests that consumer perceptions about the health benefits of organic food, often promulgated by organic food companies, leading to increased willingness to pay for organic products may be unfounded.

\section{Taste and Food Choice}

A final consideration is taste. Taste has been identified as being a significant contributor to food choice [5], particularly for younger people who have less immediate concerns with health [43]. Cultural and gender differences have been noted in the relative importance placed upon taste and health. Participants from countries such as the US [44] and UK [45] place greater importance upon health concerns and less upon the pleasure of eating than participants in countries such as France, Belgium and Finland [44,45]. Likewise, women generally place less concern upon the pleasure of eating than men also demonstrating greater concern with the healthiness of food $[44,45]$.

This paper provides data from a national survey in Australia on the prevalence and socio-demographic predictors of three FPP: consideration of price-beforehealth; purchasing organic food; and consideration of taste-before-price.

\section{Method}

This study was primarily concerned with identifying the nature and level of consumer trust in the Australian food supply [45-48], however our national survey also provided a unique opportunity to assess the prevalence and social determinants of FPP.

Households in Australia with a telephone connected and the telephone number listed in the Australian electronic white pages were eligible for random selection in 
the sample for this study. All selected households were sent an approach letter on Flinders University letterhead which detailed the purpose of the study and advised that the household would be receiving a phone call for an interview. The person, aged 18 years or over, who was last to have a birthday, was randomly selected within each contacted household to complete the survey.

In order to test question formats and sequence, and to test survey procedures, a pilot study of 52 randomly selected households was conducted prior to the main survey. Information obtained from the pilot was used to improve the questionnaire if needed.

Professional interviewers from a contracted agency conducted the study using Computer Assisted Telephone Interview (CATI) methodology from October to December 2009. A minimum of 10 call-backs were made to telephone numbers selected, to interview household members and different times of the day or evening were scheduled for each call-back. Non-contactable or responding persons were not replaced with other respondents. Each interview took an average of 14.5 minutes to complete, and ten percent of each interviewer's work was validated by the interviewer's supervisor for quality purposes.

Of the initial sample of 4100 , a sample loss of 1408 occurred due to non-connected numbers (1060), nonresidential numbers (135), ineligible household (139) and fax/modem connections (74), leaving 2692 phone numbers eligible for survey phone calls. After refusals, terminated interviews, non-contactable households, deaths, unavailable respondents and respondents who did not speak English, 1109 interviews were completed. This generated an overall sample response rate of $41.2 \%$.

To address the issue of assessing FPP, three survey items were examined, all of which were framed as follows: "I will now ask you to consider your food purchasing habits in general. This includes green grocers, sandwiches, restaurants, as well as other take away outlets." The specific survey questions were:

- Do you buy products that are a bit more expensive if the taste is better?

- Do you buy organic foods?

- Do you consider food prices before health and nutritional qualities?

Respondents were provided with response options assessing the frequency of the aforementioned items, ranging from "Often", "Sometimes" and "Seldom" to "Never". "Don't know" responses as well as refusals to answer a particular question were recorded as further response options.

One of the obvious limitations of the price-beforehealth and taste-before-price variables are that we do now know how much "a bit more" is in relation buying tastier food and we do not know exactly how much people are willing to consider when thinking about the health and nutritional qualities of food. However, the purpose of this paper is not to provide an econometric analysis or contingent valuation of food vis a vis health or taste, but to paint a picture of the types of people more likely to consider price-before-health, taste-before-price and purchasing organic foods in Australia.

\section{Data Analysis}

Demographic variables included in the analyses were age, sex, number of people in the household, number of children under 18 years of age in the household, marital status, work status, education, annual household income, the Socio-Economic Indexes for Areas (SEIFA) Index of Relative Socio-Economic Disadvantage (IRSD) as well as the Accessibility/Remoteness Index of Australia (ARIA). However, only the statistically significant predictor variables are presented.

Statistical analyses were carried out using SPSS version 17.0. As samples such as these may be disproportionate with respect to the population of interest, weighting was used to compensate for differential nonresponse and correct unequal sample inclusion probabilities. In order to reflect the Australian population structure 18 years and over, the data were weighted by age and sex reflecting the Australian Bureau of Statistics 2007 Estimated Residential Population.

For the FPP outcome variables (i.e. the three items addressing the prevalence of FPP), dichotomization procedures were also applied: "Often" and "Sometimes" responses were added together to create one level of the outcome variable ("Often/Sometimes"), while responses indicating the respondent to perform a particular action "seldom" or "never" were combined to generate the second outcome level. Responses in the form of "Don't know" and refusals to answer a question were not included in the present analysis.

All demographic predictor variables were entered into the analysis as categorical variables, the individual levels of which are summarized in Table 1. Bivariate logistic regression analyses were performed to examine the relationship between the individual demographic predictors and the various food purchasing habits. Only items showing an association at the $p<0.25$ level were entered into multiple binary logistic regression analyses [49]. Following suggestions by Field [50], for the purposes of the present investigation the method of choice for conducting regression analyses was to enter relevant predictor variables in one block rather than stepwise procedures. Predictor variables that were entered into the model but returned as not significant were in turn tested against 
Table 1. Summary of categorical predictor variables.

\begin{tabular}{|c|c|c|}
\hline \multicolumn{2}{|c|}{ Demographic predictor variables and associated levels } & $\mathrm{N}(\%)$ \\
\hline \multirow{4}{*}{ Age } & Under 30 years & $249(22.5)$ \\
\hline & $30-44$ years & $326(29.4)$ \\
\hline & $45-59$ years & $272(24.6)$ \\
\hline & 60 years and over & $261(23.5)$ \\
\hline \multirow{2}{*}{ Sex } & Male & $547(49.3)$ \\
\hline & Female & $562(50.7)$ \\
\hline \multirow{4}{*}{ People in household } & One person household & $177(16.0)$ \\
\hline & Two people in the household & $346(31.2)$ \\
\hline & Three to four people in the household & $403(36.4)$ \\
\hline & Five or more people in the household & $183(16.5)$ \\
\hline \multirow{4}{*}{ Children under 18 in household } & None & $674(60.8)$ \\
\hline & One & $166(15.0)$ \\
\hline & Two & $169(15.3)$ \\
\hline & Three or more & $100(9.0)$ \\
\hline \multirow{3}{*}{ Marital status } & Married/Living with partner & $665(59.9)$ \\
\hline & Separated/Divorced/Widowed & $149(13.5)$ \\
\hline & Never married & $293(26.4)$ \\
\hline \multirow{3}{*}{ Work status } & Full time employed & $507(45.7)$ \\
\hline & Part time employed/Unemployed & $228(20.6)$ \\
\hline & Economically inactive (home duties, student, retired, etc.) & $372(33.6)$ \\
\hline \multirow{3}{*}{ Education } & No schooling to secondary & $490(44.2)$ \\
\hline & Trade, certificate, diploma & $345(31.1)$ \\
\hline & Degree or higher & $274(24.7)$ \\
\hline \multirow{4}{*}{ Annual household income } & Up to $\$ 30,000$ & $212(22.6)$ \\
\hline & $\$ 30,001-\$ 60,000$ & $231(24.6)$ \\
\hline & $\$ 60,001-\$ 100,000$ & $253(27.0)$ \\
\hline & $\$ 100,001$ or more & $243(25.9)$ \\
\hline
\end{tabular}

models containing only significant predictor variables. This process allowed for the comparison of several models, resulting in a final model containing only variables, which significantly contributed to the model fit. For each outcome variable, predictor variables included in the regression model were checked for multicollinearity.

\section{Results}

Table 2 presents descriptive analyses of the responses to each of the three FPP. Of the respondents $88 \%$ said that they "Sometimes/Often" pay more for food products if the taste is better $(\mathrm{n}=968)$ compared to $12 \%(\mathrm{n}=130)$ who said they "Never/Seldom" pay more if the taste is better. Responses were more evenly distributed for the survey item addressing the purchase of organic products $(53 \%(\mathrm{n}=575)$ "Never/Seldom" versus 47\% $(\mathrm{n}=513)$ "Sometimes/Often") and whether participants considered food prices before health and nutritional qualities $(48 \%$ $(\mathrm{n}=522)$ "Never/Seldom" versus 52\% $(\mathrm{n}=573)$ "Sometimes/Often").

\section{Demographic Predictors of Food Purchasing Practices}

Results of the multivariate regression analyses have been organized by demographic predictor variables. The fit indices of the individual regression models and parameter estimates are reported in Table 3.

\section{1) Sex}

Sex emerged as a strong predictor for various FPP, namely paying more for food if the taste is better and considering prices before quality. Female respondents were over twice as likely as males to pay more for food if it tasted better $(\mathrm{OR}=2.2, \mathrm{p}<0.001)$ and $40 \%$ less likely than their male counterparts to state that they "Sometimes/Often" consider food prices before quality $(\mathrm{OR}=$ $0.6, p<0.001)$. This however is in line with the aforementioned findings as it suggests that women are more likely than men to prioritize food quality before price.

\section{2) Age}

Age was a predictor of respondents putting price before quality. Survey participants between 45 and 59 years 

or Organic Foods in Australia?

Table 2. Summary of sample size and response patterns across food practice variables.

\begin{tabular}{cccc}
\hline Survey item & "Never/Seldom" N (\%) & "Sometimes/Often" N (\%) & Sample size N \\
\hline Do you buy products that are a bit more expensive if the taste is better? & $130(11.9)$ & $968(88.1)$ & 1098 \\
Do you buy organic foods? & $575(52.8)$ & $513(47.2)$ & 1088 \\
Do you consider food prices before health and nutritional qualities? & $522(47.7)$ & $573(52.3)$ & 1095 \\
\hline
\end{tabular}

Table 3. Parameter estimates for regression models $\left(\chi^{2}\right.$, df, p), predictor variables (Wald $\chi^{2}$, df, $\left.\mathbf{p}\right)$ and individual predictor variable levels (OR, 95\% CI, p), organized by FPP.

\begin{tabular}{|c|c|c|c|}
\hline & Pay more if taste is better & Buy organic foods & Price before quality \\
\hline Model fit: $\chi^{2}(\mathrm{df})$ & $64.87(4)^{* * *}$ & $27.9(7)^{* * *}$ & $35.33(6)^{* * *}$ \\
\hline Sex (Male) & $12.56(1)^{* * *}$ & & $12.35(1)^{* * *}$ \\
\hline Female & $2.2^{* * *}(1.4-3.4)$ & & $0.6^{* * *}(0.5-0.8)$ \\
\hline Age ( $<30$ years $)$ & & & $16.98(3)^{* *}$ \\
\hline $30-44$ years & & & $0.9(0.6-1.2)$ \\
\hline $45-59$ years & & & $0.6^{* *}(0.4-0.9)$ \\
\hline $60+$ years & & & $0.5^{* * *}(0.4-0.8)$ \\
\hline Children (None) & & $8.14(3)^{*}$ & \\
\hline One & & $1.5^{*}(1.1-2.2)$ & \\
\hline Two & & $1.1(0.8-1.6)$ & \\
\hline Three or more & & $0.8(0.5-1.2)$ & \\
\hline Education ( $\leq$ secondary) & & & $6.09(2)^{*}$ \\
\hline Trade, cert, diploma & & & $0.9(0.7-1.3)$ \\
\hline Degree or higher & & & $0.7 *(0.5-0.9)$ \\
\hline Household inc $(<\$ 30 \mathrm{~K})$ & $48.63(3)^{* * *}$ & & \\
\hline$\$ 30,001-\$ 60,000$ & $1.9^{*}(1.2-3.1)$ & & \\
\hline$\$ 60,001-\$ 100,000$ & $5.5^{* * *}(2.9-10.4)$ & & \\
\hline$>\$ 100,001$ & $7.9^{* * *}(3.9-16.0)$ & & \\
\hline Work status (Full time) & & $9.72(2)^{* *}$ & \\
\hline Part time/Unemployed & & $0.6^{* *}(0.5-0.9)$ & \\
\hline Economically inactive & & $0.7^{*}(0.5-0.9)$ & \\
\hline Marital status (Married/Living w. partner) & & $7.92(2)^{*}$ & \\
\hline Divorced/Sep./Widow & & $0.8(0.5-1.2)$ & \\
\hline Never married & & $1.4^{*}(1.0-1.8)$ & \\
\hline
\end{tabular}

Note: ${ }^{* * *}$ p significant at $<0.001 ;{ }^{* *}$ p significant at $0.01 ;{ }^{*}$ p significant at $0.05 ;{ }^{*}$ trend for significance $\mathrm{p}<0.08$.

of age were $40 \%$ less likely to report considering price before quality $(\mathrm{OR}=0.6, \mathrm{p}<0.01)$ than the youngest respondents). The oldest age cohort (i.e. individuals aged 60 years and above) were half as likely put price before quality $(\mathrm{OR}=0.5, \mathrm{p}<0.001)$ than their under 30 coun-

\section{terparts.}

\section{3) Children in the Household}

The number of children under 18 years cohabiting in the same household was a factor which significantly predicted buying organic products. For buying organic 
products, the likelihood of doing so more frequently was found to be $50 \%$ higher for respondents with one child compared to respondents without children $(\mathrm{OR}=1.5, \mathrm{p}<$ 0.05).

\section{4) Education}

The only FPP for which education was found to be significant was the frequency with which respondents reported to consider price before the health or nutritional quality of food. Respondents with a degree or higher were $30 \%$ less likely to say that they "Sometimes/Often" consider price before quality compared to respondents with secondary schooling or lower $(\mathrm{OR}=0.7, \mathrm{p}<0.05)$, indicating that they are more likely to think about the health and/or nutritional benefits of food before their cost.

\section{5) Household Income}

The only FPP for which annual household income was found to be significant was the frequency with which respondents reported to pay more for food if warranted by better taste. Relative to the lowest household income group $(<\$ 30,000$ per annum), respondents between $\$ 30,001$ and $\$ 60,000$ were $90 \%$ more likely to state that they "Sometimes/Often" pay more for food if the taste is better $(\mathrm{OR}=1.9, \mathrm{p}<0.05)$, while odds ratios were markedly higher for those between $\$ 60,001$ and $\$ 100,000$ $(\mathrm{OR}=5.5, \mathrm{p}<0.001)$ and even more so for those with more than $\$ 100,000(\mathrm{OR}=7.9, \mathrm{p}<0.001)$. The general pattern discernable from the odds ratios observed is that the more household income respondents had available, the more likely they were say that they "Sometimes/ Often" paid more for food if warranted by better taste.

\section{6) Marital Status}

The only FPP for which marital status approached statistical significance as a predictor variable was buying organic products, where the likelihood for doing so "Sometimes/Often" was $40 \%$ higher for individuals who have never been married compared with those who were married or living with a partner $(\mathrm{OR}=1.4, \mathrm{p}<0.05)$.

\section{7) Work Status}

The frequency with which survey participants indicated to buy organic products was predicted by work status: Buying organic products "Sometimes/Often" was $40 \%$ less likely for part-time employed or unemployed respondents $(\mathrm{OR}=0.6, \mathrm{p}<0.01)$ and $30 \%$ less likely for economically inactive respondents $(\mathrm{OR}=0.7, \mathrm{p}<0.05)$ compared to those in full time employment.

\section{Limitations of the Study}

We acknowledge several weaknesses in this crosssectional study. The self-report nature of the data collection could result in socially desirable responses or problems with recall. The response rate of nearly $41 \%$ is moderately acceptable for this type of survey but the potential for survey non-response bias is acknowledged. Response rates are declining in surveys based on all forms of interviewing [51,52] as people have become more active in protecting their privacy. The growth of telemarketing has disillusioned the community and diminished the success of legitimate social science research by means of telephone-based surveys. The use of a telephone as the mode of data collection could also result in bias. The EWP sampling strategy used in this research includes mobile phone with up to $8 \%$ of interviews undertaken on this medium. Although possible bias associated with EWP as the sampling frame is acknowledged, research on this issue has previously been undertaken [53,54]. In addition, the growing use of mobile telephones has contributed to declining response rates for surveys administrated via telephone [55]. Notwithstanding, the strength of this study includes the random nature of the sample and the large number and variety of the associated variables.

\section{Discussion}

This research is based on a large scale randomly selected sample of the Australian adult population. It has highlighted the prevalence and social determinants of a range of FPP focusing on purchasing organic food, putting price-before-health, and putting taste-before-price.

Univariate and multivariate analyses have been undertaken on three specific FPP. Ten separate socio-demographic variables were assessed against each food practice and results indicate that sex, age, number of people in each household and education were the variables most likely to be included in the final multivariate models. Variables related to household income, work status and marital status were included in only one of the six regression models. IRSD, ARIA and number of people in the household were not included in any of the final multivariate models.

In terms of the prevalence of the FPP, the majority of respondents stated that they pay more for food if it tasted better (88\%). This suggest the key importance of food taste as a food practice. It is surprising, given rising food costs and economic downturn, that so many people are prepared to pay more for food if it tastes better. Obviously people with the economic capital have always been able to "buy taste" [2], but our finding of $88 \%$ suggests that it is more than just the high SES respondents who have a taste-before-price food purchasing practice. That said, the multivariate regression model found that people with an income over $\$ 100,000$ are almost 8 times more likely to say that they "Sometimes/Often" purchased food in this manner as compared to people with an income less than $\$ 30,000$. In addition, 
females were twice as likely as males to also have a taste-before-price food purchasing practice.

What we do not know from these data are "how much would people be willing to pay for taste-before-price?", and "for what types of food would this be the case?" It may be the case that people would be willing to pay more for tastier "high end" food such as lobster and fillet steak, but less willing to do this for "basic food" such as fruit and vegetables. It may also be the case that certain social groups will be more willing to pay extra for foods which maintain their "distinction" within society [2]. None of these questions were dealt with in our study, but would be very worthy questions for future research.

Findings from our study were less consensual on the prevalence of responding "Sometimes/Often" for the other two FPP: buying organic food $(47 \%)$ and consider price before health and nutritional qualities of food (52\%).

With reference to buying organic foods, it is interesting to note a $50 \%$ increase in households with one child, but then no significance for households with more children. We can understand the likelihood of purchasing organic food due to the perception and marketing about the nutritional and health benefits of organic food, even though the systematic reviews can find no evidence of this [41,42]. In a study investigating the food purchasing habits of mothers, it was found that the foods mother's purchase for themselves was based on motivations of calorie content, availability, cost and time taken in preparation. In contrast, the motivations for the foods purchased for children were based on the long-term health and nutritional value [56]. However, the lack of association with families with two or more children does not conform to these ideas. It may be the case that the cost of organic food is prohibitive for many families with two or more children. Whilst there was no association with household income or education, as we may have expected, there was an association with work status, whereby people with part-time employment, unemployed or economically inactive were between $30 \%-40 \%$ less likely to buy organic foods. It may be the case that people in full-time employment have both the economic and cultural capital required to purchase organic food. However, we would have also expected people with a degree and higher household incomes to be more likely to "Sometimes/Often" purchase organic foods, given Bourdieu's argument that the purchasing of organic food can be understood as a form of symbolic and cultural capital [2] or elevated social status [57]. This is further elaborated by Guthman [58] who argues that organic food is viewed within the public imagination as "reflexive eating par excellence" (p. 46), and therefore an activity which is concentrated within those with enough economic and cultural capital. Indeed, O'Neill [59] argues that since "capital" (economic, cultural, symbolic etc) is a positional good, its value is depleted if greater numbers of people have access to it, since it becomes "normal", and therefore various mechanisms are instigated in order to reduce access and keep it "special". However, our data do not wholly support this theory although further research is required.

In terms of the FPP related to considering the price of food before its health or nutritional quality (what we call price-before-health), there is a clear and consistent pattern whereby females, older people and more educated people were less likely to purchase food in this manner. In other words, they were more likely to consider the health and nutritional quality of food before its price. In broad terms, this fits with literature suggesting that quality rather than price is of paramount importance to consumers [60]. However, our findings reveal the heterogeneous nature of this, since men, younger people and people with lower educational qualifications were more likely to use price-before-health as a food purchasing decision. In our study, it seems that men are particularly price-sensitive, being less willing to pay for price-beforetaste and more willing to consider price-before-health. This fits with literature about risk taking behaviours for both men and young people [61-63] but warrants further research and policy action in order to raise the awareness of the importance of considering nutrition and health when purchasing food. In terms of people with lower educational qualifications, this price-sensitivity may be a function of lower incomes in this group, but again may raise the need for research and policy action on food literacy.

Our findings identify that despite the majority of participants stating that they will pay more for taste, it remains unknown as to whether the desired tastes are of high or low nutritional value. More importantly are our findings which suggest that higher income individuals are willing to spend more for healthier food, whether it is for image or health, whereas men, younger people and lower educated individuals are more likely to consider price before health. This is of paramount importance given recent shifts in Australian policy towards health promotion, and the prevention of chronic diseases with a particular focus on men's health, and on educating young Australians about the importance of healthy eating. These campaigns are insignificant if the current economic climate and consequential rising costs of food renders these initiatives impractical.

\section{REFERENCES}

[1] K. Seear, S. Fraser, J. Wright, J. Maher and A. Petersen, "Peeling away the Onion. Report on a National Consulta- 
tion on Childhood Obesity Research, Policy and Practice in Australia," Centre for Women's Studies and Gender Research, Monash University, 2010.

[2] P. Bourdieu, "Distinction: A Social Critique of the Judgement of Taste," Routledge, London, 1984.

[3] P. Bourdieu, "Outline of a Theory of Practice," Cambridge University Press, Cambridge, 1977.

[4] A. Sayer, "The Moral Significance of Class," Cambridge University Press, Cambridge, 2005. doi:10.1017/CBO9780511488863

[5] K. Glanz, M. Basil, K. Maibach, J. Goldberg and D. Snyder, "Why Americans Eat What They Do: Taste, Nutrition, Cost, Convenience and Weight Concerns as Influences on Food Consumption," Journal of the American Dietetics Association, Vol. 98, No. 10, 2003, pp. 11181126. doi:10.1016/S0002-8223(98)00260-0

[6] A. Drewnowski and N. Darmon, "The Economics of Obesity. Diet, Energy Density and Energy Costs," The American Journal of Clinical Nutrition, Vol. 82, No. 1, 2005, pp. 265-273.

[7] A. Drewnowski and S. Specter, "Poverty and Obesity: The Role of Energy Density and Energy Costs," American Journal of Clinical Nutrition, Vol. 79, No. 1, 2004, pp. 6-16.

[8] M. Harrison, T. Coyne, A. Lee, D. Leonard, S. Lowson, A. Groos and B. Ashton, "The Increasing Cost of the Basic Foods Required to Promote Health in Queensland," Medical Journal of Australia, Vol. 186, No. 1, 2007, pp. 9-14

[9] Australian Bureau of Statistics, "Consumer Price Index Australia: June Quarter 2008,” 2008.

[10] G. Turrell and A. M. Kavanagh, "Socio-Economic Pathways to Diet: Modelling the Association between SocioEconomic Position and Food Purchasing Behaviour," Public Health Nutrition, Vol. 9, No. 3, 2006, pp. 375-383. doi:10.1079/PHN2005850

[11] M. S. Harrison, T. Coyne, A. J. Lee and D. Leonard, "The Increasing Cost of the Basic Foods Required to Promote Health in Queensland," Medical Journal of Australia, Vol. 186, No. 1, 2007, p. 9.

[12] S. Booth and A. Smith, "Food Security and Poverty in Australia - Challenges for Dietitians," Australian Journal of Nutrition and Dietetics, Vol. 58, No. 3, 2001, pp. 150156.

[13] N. Wrigley, D. Warm, B. Margetts and M. Lowe, "The Leeds 'Food Deserts' Intervention Study: What the Focus Groups Reveal," International Journal of Retail \& Distribution Management, Vol. 32, No. 2, 2004, pp. 123-136. doi:10.1108/09590550410521798

[14] S. Kirkpatrick and V. Tarasuk, "Adequacy of Food Spending Is Related to Housing Expenditures among LowerIncome Canadian Households," Public Health Nutrition, Vol. 10, No. 12, 2007, pp. 1464-1473.

[15] J. Douglas, "Food Insecurity in Northern Adelaide," SACOSS, 2006.

[16] I. Law, P. Ward and J. Coveney, "Food Insecurity in
South Australian Single Parents: A Livelihoods Framework Approach," Critical Public Health, in press. http://www.tandfonline.com/doi/abs/10.1080/09581596.2 011.619963

[17] K. Alaimo, C. M. Olson, E. Frongillo and R. Briefel, "Food Insufficiency, Family Income, and Health in US Preschool and School-Aged Children," American Journal of Public Health, Vol. 91, No. 5, 2001, pp. 781-786. doi:10.2105/AJPH.91.5.781

[18] K. Martin and A. Ferris, "Food Insecurity and Gender Are Risk Factors for Obesity," Journal of Nutrition Education and Behaviour, Vol. 39, No. 1, 2007, pp. 31-36. doi:10.1016/j.jneb.2006.08.021

[19] H. Seligman, A. Bindman, E. Vittinghoff, A. Kanaya and M. Kushel, "Food Insecurity Is Associated with Diabetes Mellitus: Results from the National Health Examination and Nutrition Examination Survey (NHANES) 19992002," Journal of General Internal Medicine, Vol. 22, No. 7, 2007, pp. 1018-1023. doi:10.1007/s11606-007-0192-6

[20] N. Vozoris and V. Tarasuk, "Household Food Insufficiency Is Associated with Poorer Health," The Journal of Nutrition, Vol. 133, No. 1, 2003, pp. 120-126.

[21] S. Kirkpatrick and V. Tarasuk, "Food Insecurity Is Associated with Nutrient Inadequacies among Canadian Adults and Adolescents," Journal of Nutrition, Vol. 138, No. 3, 2008, pp. 604-612.

[22] W. Foley, P. Ward, P. Carter, J. Coveney, G. Tsourtos and A. Taylor, "An Ecological Analysis of Factors Associated with Food Insecurity in South Australia 20022007," Public Health Nutrition, Vol. 13, 2010, pp. 215 221.

[23] G. Marks, I. Coles-Rutishauser, K. Webb and P. Picton, "Key Food and Nutrition Data for Australia 1990-1999," Commonwealth of Australia, Canberra, 2001.

[24] C. Shannon, "Acculturation: Aboriginal and Torres Strait Islander Nutrition," Asia Pacific Journal of Clinical Nutrition, Vol. 11, Suppl. 3, 2002, pp. S576-S578.

[25] D. Gallegos, P. Ellies and J. Wright, "Still There's No Food! Food Insecurity in a Refugee Population in Perth, Western Australia," Nutrition \& Dietetics, Vol. 65, No. 1, 2008, pp. 78-83. doi:10.1111/j.1747-0080.2007.00175.x

[26] K. Wong, J. Coveney, P. Ward, R. Muller, P. Carter, F. Verity and G. Tsourtos, "Availability, Affordability and Quality of a Healthy Food Basket in Adelaide, South Australia," Nutrition and Dietetics, Vol. 68, No. 1, 2011, pp. 8-14. doi:10.1111/j.1747-0080.2010.01490.x

[27] E. Dowler, "Budgeting for Food on a Low Income in the UK: The Case of Lone-Parent Families," Food Policy, Vol. 22, No. 5, 1997, pp. 405-417. doi:10.1016/S0306-9192(97)00031-6

[28] A. Donkin, E. Dowler, S. Stevenson and S. Turner, "Mapping Access to Food in a Deprived Area: The Development of Price and Availability Indices," Public Health Nutrition, Vol. 3, No. 1, 2000, pp. 31-38. doi:10.1017/S1368980000000057

[29] A. Ellaway and S. Macintyre, "Shopping for Food in 
Socially Contrasting Localities," British Food Journal, Vol. 102, No. 1, 2000, pp. 52-59. doi:10.1108/00070700010310632

[30] L. Mcintyre, "Food Security: More Than a Determinant of Health," Policy Options, Vol. 24, No. 3, 2003, pp. 4651.

[31] G. Turrell and A. Kavanagh, "Socio-Economic Pathways to Diet: Modelling the Association between Socio-Economic Position and Food Purchasing Behaviour," Public Health Nutrition, Vol. 9, No. 3, 2006, pp. 375-383. doi:10.1079/PHN2005850

[32] J. Coveney and L. O'Dwyer, "Effects of Mobility and Location on Food Access," Health \& Place, Vol. 15, No. 1, 2009, pp. 45-55. doi:10.1016/j.healthplace.2008.01.010

[33] P. Kristiansen, A. Mitchell, N. Bez and A. Monk, "Australian Organic Market Report 2010," Biological Framers of Australia, Chermside, 2010.

[34] Soil Association, "Organic Market Report," Soil Association, Briston, 2010.

[35] C. Williams, "Nutritional Quality of Organic Food: Shades of Grey or Shades of Green?" Proceedings of the Nutrition Society, Vol. 61, No. 1, 2002, pp. 19-24. doi:10.1079/PNS2001126

[36] G. Harper and A. Makatouni, "Consumer Perception of Organic Food Production and Farm Animal Welfare," British Food Journal, Vol. 104, No. 3-5, 2002, pp. 287299. doi:10.1108/00070700210425723

[37] E. K. Yiridoe, S. Bonti-Ankomah and R. C. Martin, "Comparison of Consumer Perceptions and Preference toward Organic versus Conventionally Produced Foods: A Review and Update of the Literature," Renewable Agriculture and Food Systems, Vol. 20, No. 4, 2005, pp. 193-205. doi:10.1079/RAF2005113

[38] M. Magnusson, A. Arvola, U.-K. Hursti, L. Ãberg and P. Sjoden, "Choice of Organic Foods Is Related to Perceived Consequences for Human Health and to Environmentally Friendly Behaviour," Appetite, Vol. 40, No. 2, 2003, pp. 109-117. doi:10.1016/S0195-6663(03)00002-3

[39] J. Cranfield, B. Deaton and S. Shellikeri, "Evaluating Consumer Preferences for Organic Food Production Standards," Canadian Journal of Agricultural Economics, Vol. 57, No. 1, 2009, pp. 99-107.

[40] P. Williams, E. Stirling and N. Keynes, "Food Fears: A National Survey on the Attitudes of Australian Adults about the Safety and Quality of Food," Asia Pacific Journal of Clinical Nutrition, Vol. 13, No. 1, 2004, pp. 32-39.

[41] A. Dangour, S. Dodhia, A. Hayter, E. Allen, K. Lock and R. Uauy, "Nutritional Quality of Organic Foods: A Systematic Review," The American Journal of Clinical Nutrition, Vol. 60, 2009, pp. 680-685. doi:10.3945/ajen.2009.28041

[42] A. Dangour, K. Lock, A. Hayter, A. Aikenhead, E. Allen and R. Uauy, "Nutrition-Related Health Effects of Organic Foods: A Systematic Review," The American Journal of Clinical Nutrition, Vol. 92, No. 1, 2010, pp. 203210. doi:10.3945/ajen.2010.29269

[43] D. Neumark-Sztainer, M. Story, C. Perry and M. Casey,
"Factors Influencing Food Choices of Adolescents: Findings from Focus-Group Discussions with Adolescents," Journal of the American Dietetic Society, Vol. 99, No. 8, 1999, pp. 929-937. doi:10.1016/S0002-8223(99)00222-9

[44] P. Rozin, C. Fischler, S. Imada, A. Saubin and A. Wrzesniewski, "Attitudes to Food and the Role in Life in the USA, Japan, Flemish Belgium and France: Possible Implications for the Diet-Health Debate," Appetite, Vol. 33, No. 2, 1999, pp. 163-180. doi:10.1006/appe.1999.0244

[45] K. Roininen, H. Tuorila, E. Zandstra, C. de Graaf, K. Vehkalahti, K. Stubenitsky and D. Mela, "Differences in Health and Taste Attitudes and Reported Behaviour among Finnish, Dutch and British Consumers: A CrossNational Validation of the Health and TASTE Attitude Scales (HTAS)," Appetite, Vol. 37, 2001, pp. 33-45. doi:10.1006/appe.2001.0414

[46] J. Henderson, J. Coveney and P. Ward, "Who Regulates food? Australians' Perceptions of Responsibility for Food Safety," Australian Journal of Primary Health, Vol. 16, No. 4, 2010, pp. 344-351. doi:10.1071/PY10011

[47] J. Henderson, J. Coveney, P. Ward and A. Taylor, "Governing Childhood Obesity: Framing Regulation of Fast Food Advertising in the Australian Print Media," Social Science and Medicine, Vol. 69, No. 9, 2009, pp. 14021408. doi:10.1016/j.socscimed.2009.08.025

[48] P. Ward, J. Henderson, J. Coveney and S. Meyer, "How Do South Australian Consumers Negotiate and Respond to Information in the Media about Food and Nutrition? The Importance of Risk, Trust and Uncertainty," Journal of Sociology, Vol. 48, No. 1, 2012, pp. 21-39. doi: $10.1177 / 1440783311407947$

[49] D. Hosmer and S. Lemeshow, "Applied Logistic Regression," 2nd Edition, John Wiley \& Sons, New York, 2000. doi: $10.1002 / 0471722146$

[50] A. Field, "Discovering Statistics Using SPSS," 3rd Edition, Sage, London, 2009.

[51] R. Curtin, S. Presser and E. Singer, "Changes in Telephone Survey Nonresponse over the Past Quarter Century," Public Opinion Quarterly, Vol. 69, No. 1, 2005, pp. 87-88. doi:10.1093/poq/nfi002

[52] R. M. Groves, "Nonresponse Rates and Nonresponse Bias in Household Surveys," Public Opinion Quarterly, Vol. 70, No. 5, 2006, pp. 646-675. doi:10.1093/poq/nf1033

[53] D. Wilson, G. Starr, A. Taylor and E. Dal Grande, "Random Digital Dialling and Electronic White Pages Samples Compared," Australian and New Zealand Journal of Public Health, Vol. 23, No. 6, 1999, pp. 627-633.

[54] E. Dal Grande, A. Taylor and D. Wilson, "Is There a Difference in Health Estimates between People with Listed and Unlisted Telephone Numbers?" Australian \& New Zealand Journal of Public Health, Vol. 29, No. 5, 2005, pp. 448-456. doi:10.1111/j.1467-842X.2005.tb00225.x

[55] D. Dilman, G. Phelps, R. Tortora, K. Swift, J. Kohrell, J. Berck and B. Messer, "Response Rate and Measurement Differences in Mixed Mode Surveys Using Mail, Telephone, Interactive Voice Response (IVR) and the Inter- 
net," Social Science and Medicine, Vol. 38, No. 1, 2009, pp. 1-18. doi:10.1016/j.ssresearch.2008.03.007

[56] T. Alderson and J. Ogden, "What Do Mothers Feed Their Children and Why?" Health Education Research, Vol. 14, No. 6, 1999, pp. 717-727. doi:10.1093/her/14.6.717

[57] K. Soper, "Re-Thinking the 'Good Life': The Citizenship Dimension of Consumer Disaffection with Consumerism," Journal of Consumer Culture, Vol. 7, No. 2, 2007, pp. 205-229. doi:10.1177/1469540507077681

[58] J. Guthman, "Fast Food/Organic Food: Reflexive Tastes and the Making of "Yuppie Chow'," Social and Cultural Geography, Vol. 4, No. 1, 2003, pp. 35-48. doi:10.1080/1464936032000049306

[59] J. O’Neill, "Economy, Equality and Recognition," In: L. Ray and A. Sayer, Eds., Culture and Economy after the Cultural Turn, Sage, London, 1999, pp. 76-91.

[60] F. Wang, J. Zhang, W.-S. Mu, Z.-T. Fu and X.-S. Zhang, "Consumers' Perception towards Quality and Safety of
Fishery Products, Beijing, China," Food Control, Vol. 20, No. 10, 2009, pp. 918-922. doi:10.1016/j.foodcont.2009.01.008

[61] K. C. Backett-Milburn, W. J. Wills, S. Gregory and J. Lawton, "Making Sense of Eating, Weight and Risk in the Early Teenage Years: Views and Concerns of Parents in Poorer Socio-Economic Circumstances," Social Science \& Medicine, Vol. 63, No. 3, 2006, pp. 624-635. doi:10.1016/j.socscimed.2006.02.011

[62] E. O. Nightingale and B. Fischhoff, "Adolescent Risk and Vulnerability: Overview," Journal of Adolescent Health, Vol. 31, Suppl. 1, 2002, pp. S3-S9. doi:10.1016/S1054-139X(02)00413-5

[63] J. Byrnes, D. Miller and W. Schafer, "Gender Differences in Risk Taking: A Meta Analysis," Psychological Bulletin, Vol. 125, No. 3, 1999, pp. 367-383. 